\title{
Prostate Cancer Research at the Crossroads
}

\author{
Michael M. Shen ${ }^{1}$ and Mark A. Rubin ${ }^{2,3}$ \\ ${ }^{1}$ Departments of Medicine, Genetics and Development, Urology, and Systems Biology, Herbert Irving \\ Comprehensive Cancer Center, Columbia University Medical Center, New York, New York 10032 \\ ${ }^{2}$ Englander Institute for Precision Medicine, Department of Pathology and Laboratory Medicine, Sandra \\ and Edward Meyer Cancer Center, Weill Cornell Medicine, New York, New York 10021 \\ ${ }^{3}$ Department of BioMedical Research, University of Bern and Inselspital, 3008 Bern, Switzerland \\ Correspondence: mshen@columbia.edu; mark.rubin@dbmr.unibe.ch
}

Thenting he past 25 years have heralded a renaissance of transformative research on prostate cancer. Inspired by patient-advocacy groups, increases in government and private funding of research, and greater awareness of the disease, an influx of talented researchers entered the field of prostate cancer research, often from other fields. These researchers have spearheaded important advances, including sophisticated genomic analyses and the development of second-generation, more effective, anti-androgen therapies. As a result, there has been a sustained burst of key findings that have shaped our current understanding of the disease and its treatment.

Worldwide, prostate cancer is the second most commonly diagnosed nonskin cancer, with an estimated 1.3 million new cases in 2018 (Bray et al. 2018). Among American men, prostate cancer represents the most frequently diagnosed cancer, with an estimate of more than 164,000 new cases in 2018, and represents the second leading cause of cancer death, with more than 29,000 deaths (Siegel et al. 2018). On average, one in nine American men will receive a diagnosis of prostate cancer during their lifetime (Siegel et al. 2018). These statistics underscore the health impact of prostate cancer as a disease entity and justify continuing research into its etiology and treatment.

Recent advances in prostate cancer research have brought the field to an important crossroad, at a nexus where basic and translational findings have begun to make significant impacts in the clinic. Consequently, we have assembled a distinguished panel of active investigators to provide an overview of the exciting developments that are occurring at the frontlines of nearly every area of prostate cancer research. Our ambitious goal is to survey the current state of basic and translational research in prostate cancer and to outline future directions for the field. Below, we introduce several of the primary questions that will be addressed in this collection.

\section{WHY IS THE PROSTATE A TARGET OF ONCOGENIC TRANSFORMATION?}

Despite the prevalence of prostate cancer, it remains unclear why this walnut-sized tissue of unremarkable appearance should represent a potent target of oncogenic transformation. The human prostate is a secondary sexual tissue that is highly regulated by androgens, yet other tissues with similar features languish in obscurity. Why should the prostate be different from

Editors: Michael M. Shen and Mark A. Rubin

Additional Perspectives on Prostate Cancer available at www.perspectivesinmedicine.org

Copyright (C) 2019 Cold Spring Harbor Laboratory Press; all rights reserved; doi: 10.1101/cshperspect.a036277

Cite this article as Cold Spring Harb Perspect Med 2019;9:a036277 
M.M. Shen and M.A. Rubin

neighboring tissues such as the seminal vesicle and ampullary glands?

Clues to the possible significance of the prostate as a major site for human cancer may lie in its developmental origins. The prostate is an endodermal tissue that arises from the primitive urogenital sinus, which itself represents a caudal extension of the hindgut. Thus, the bladder and prostate represent the most posterior of the tissues that develop from the gut endoderm. In this regard, the prostate is part of a continuum of tissues generated along the anterior-posterior extent of the gut tube, most of which correspond to important sites of human cancer (e.g., lung, liver, pancreas, and colorectal). In contrast, several other tissues of the male reproductive system such as the seminal vesicle are not of endodermal origin but instead arise from a distinct embryonic germ layer-namely, the mesoderm - and thus might be intrinsically more resistant to oncogenic transformation.

Classical studies by the Cunha laboratory, starting in the 1970s, began to elucidate the processes by which the prostate is induced to form from the urogenital sinus (Cunha et al. 1987). These studies used tissue recombination approaches in which epithelial and mesenchymal components of developing tissues could be dissociated and reassembled in grafts. Interestingly, these studies showed that the identity of many urogenital tissues including the prostate is primarily specified by the mesenchyme, not by the epithelium. Thus, the stromal components of urogenital tissues also play a key role in determining whether they represent a target of oncogenic transformation.

Another feature of the prostate that is notable in the context of oncogenic transformation is its relative growth quiescence. Notably, prostate epithelial cells rarely undergo cell division during normal tissue homeostasis, and thus might seem to represent unlikely targets for oncogenic transformation. However, the growth quiescence of prostate epithelium can be rapidly altered by tissue injury or inflammation due to infection (prostatitis), leading to its rapid proliferation as well as altered specification of epithelial cell types (Kwon et al. 2014; Toivanen et al. 2016). Thus, enhanced understanding of stem cell properties, prostate organogenesis, and stromal-epithelial interactions are all likely to be relevant for prostate cancer etiology.

\section{HOW DOES ANDROGEN SIGNALING REGULATE KEY FEATURES OF PROSTATE TUMORIGENESIS?}

The seminal work of Huggins and Hodges in the 1940s introduced androgen-deprivation therapy, thereby changing the treatment landscape for prostate cancer. In the subsequent decades, many studies have shown that androgen signaling plays a key role in nearly every aspect of prostate development, function, and oncogenic transformation. A wealth of mechanistic detail at the molecular level has been uncovered to describe how androgen receptor (AR), a member of the nuclear receptor superfamily, interacts with other transcriptional regulators to regulate key properties of the prostate, and how these interactions are disrupted by androgen withdrawal.

Nonetheless, following androgen-deprivation therapy, prostate cancer invariably will recur, despite the lack of circulating androgens. For many decades, this relapsed form of prostate cancer was termed "androgen-independent," as it was thought to persist in the near absence of androgens. However, several groups discovered that this was a misnomer, as a significant proportion of "androgen-independent" prostate tumors were capable of de novo androgen biosynthesis and thus were not independent of androgens at all (Mostaghel et al. 2007; Locke et al. 2008; Montgomery et al. 2008). Moreover, key findings made by Sawyers and colleagues showed that the primary feature of "androgenindependence" in prostate tumor xenografts was increased AR expression (Chen et al. 2004). These and other findings underscored that the diversity of molecular mechanisms leading to "androgen independence" of prostate tumors had as their common feature the up-regulation of AR pathway activity. For example, such molecular mechanisms include AR amplification, activating mutations of $\mathrm{AR}$, and expression of novel AR splice variants (Antonarakis et al. 2014; Miyamoto et al. 2015). Consequently, a new terminology of "castration resistance" was 
introduced to replace the former "androgen-independent" nomenclature, and we now refer to castration-resistant prostate cancer (CRPC) as emerging after androgen-deprivation therapy.

These key insights into the mechanisms of castration resistance have led to the development of improved pharmacological agents for targeting androgen biosynthesis and AR function, including abiraterone and enzalutamide (Ang et al. 2009; Tran et al. 2009). The introduction of these second-generation anti-androgens has had a major impact on clinical practice and has improved patient outcomes. However, prostate tumors will also become resistant to these anti-androgen agents, and the molecular mechanisms that underlie this second-generation CRPC represent a topic of many ongoing studies. In contrast with "first-generation" CRPC, these new forms of CRPC often result in prostate tumors that are AR-indifferent and thus can be considered AR-independent. These AR-indifferent CRPC variants often display unusual pathological features, such as neuroendocrine differentiation, which are associated with aggressive tumor phenotypes (Beltran et al. 2011).

Consequently, the molecular basis for neuroendocrine differentiation and other forms of cellular plasticity in CRPC represents the subject of intense investigation (Ku et al. 2017; Mu et al. 2017; Zou et al. 2017). The role of epigenetic alterations in modulating tumor plasticity is of particular interest, because epigenetic regulators may represent attractive druggable targets. More generally, greater understanding of the lineage hierarchy in prostate tumors and clonal evolution in response to therapy will be essential for the effective treatment of CRPC.

\section{WHAT ARE THE KEY GENETIC AND EPIGENETIC EVENTS THAT PROMOTE PROSTATE CANCER PROGRESSION?}

In recent years, extensive progress has been made in genomic analyses that have described the mutational spectrum of prostate cancer, including large-scale studies supported by The Cancer Genome Anatomy project (TCGA) and by Stand Up to Cancer (SU2C) (Cancer Genome
Atlas Research Network 2015; Robinson et al. 2015). In particular, these studies have highlighted the particular importance of copy number alterations and chromosomal rearrangements in driving prostate cancer tumorigenesis, and it is evident that the levels of copy number alterations are associated with tumor recurrence and cancer-specific mortality (Hieronymus et al. 2018). Notably, unlike most other solid tumors, prostate cancer initiation and early stages of progression do not generally feature frequently recurring mutations in oncogenes and tumor suppressors. For example, the most frequently mutated genes in primary prostate tumors are SPOP at $\sim 10 \%$ and TP53 at $\sim 12 \%$ (Barbieri et al. 2012; Blattner et al. 2014; Robinson et al. 2015; Armenia et al. 2018). Only in CRPC and metastatic prostate cancer do the frequencies of recurrently mutated genes rise to levels that would be typical of other solid tumors. However, why prostate cancer differs from other solid tumor types in this key regard is still poorly understood.

Given these findings, the origins of genomic instability in prostate cancer is of considerable interest. The molecular mechanisms of phenomena such as chromoplexy and chromothripsis that give rise to widespread genomic rearrangements are also highly relevant for understanding prostate tumorigenesis. One key mechanism that drives chromosomal rearrangements is the activity of AR, which can promote DNA breaks at cognate binding sites and is believed to play a central role in the formation of the TMPRSS2$E R G$ rearrangement, which occurs in $~ 50 \%$ of prostate adenocarcinomas (Tomlins et al. 2005).

The relative absence of mutations in key driving oncogenes and tumor suppressors during prostate cancer initiation is also relevant for understanding the origin of precursor stages of prostate cancer, notably prostate intraepithelial neoplasia (PIN) and prostate inflammatory atrophy (PIA). How these preneoplastic states arise from the normal prostate epithelium is of fundamental interest and may relate to central questions such as the cell type of origin as well as the distinction between indolent and aggressive forms of prostate adenocarcinoma. 
M.M. Shen and M.A. Rubin

\section{WHAT ARE THE FACTORS THAT DETERMINE SUSCEPTIBILITY TO PROSTATE CANCER?}

There has been an increasing appreciation that the epidemiology of prostate cancer needs to be understood in the context of germline genetics and ethnic disparities. It has long been known that prostate cancer is one of the most heritable solid tumors, which has led to a multitude of studies searching for "prostate cancer genes." However, the results of many genome-wide association studies (GWASs) suggest that a large number of risk variants contribute to the overall risk of prostate cancer, although variants responsible for aggressive disease have been less welldefined.

Issues related to ethnic disparities are also important for understanding the epidemiology of prostate cancer. Access to health care is not equitably distributed in many countries, and attitudes toward health care can differ widely as a result of cultural and economic factors. These nongenetic factors are important to take into account when trying to understand variation in the incidence and severity of prostate cancer in specific ethnic groups. Notably, why do African-American men have more aggressive prostate cancer? To date, genomic studies alone are unable to explain this important disparity (Huang et al. 2017), and it is likely that a complex mix of factors involving genetics and access to high-quality health care play key roles.

\section{HOW CAN PROSTATE CANCER DETECTION AND TREATMENT BE IMPROVED?}

Future avenues for improvement of prostate cancer detection and treatment are complex because of several key unresolved issues. In particular, the introduction of testing for prostatespecific antigen (PSA) revolutionized the early detection of prostate cancer, yet has also generated long-lasting controversy about its efficacy in reducing deaths due to prostate cancer (Andriole et al. 2009; Schroder et al. 2009; Shoag et al. 2016; Hu et al. 2017; US Preventive Services Task Force et al. 2018). The majority of patients with localized prostate cancer have indolent disease that can be effectively managed by ac- tive surveillance protocols, but the accurate identification of patients with aggressive prostate cancer at earlier stages of progression has remained a difficult problem. Although PSA testing is highly effective in identifying prostate cancer, it has been less successful at distinguishing between indolent versus aggressive disease. Notably, even with the advent of sophisticated molecular tests, the ability of a skilled pathologist to interpret prostate tumor histopathology still represents the gold standard for diagnosis of aggressive prostate cancer.

Because of the widespread use of PSA testing and the limitations of this biomarker, localized prostate cancer has been overtreated in Western societies. Decreasing overtreatment would have important benefits for patient quality of life by reducing the morbidity associated with treatment. To help address this problem, a number of biomarker panels have been developed that attempt to distinguish indolent from aggressive tumors, with varying degrees of success. Clearly, the identification and validation of accurate and informative biomarkers remains an important area of continuing study.

Chemoprevention has long been considered as an attractive strategy to reduce prostate cancer incidence and/or severity. Notably, the $5 \alpha$-reductase inhibitor finasteride acts as a mild anti-androgen and has been viewed as a potential means for decreasing risk of prostate cancer progression (Thompson et al. 2003). However, the mixed results obtained from this large study diminished enthusiasm for finasteride as a chemopreventive agent. To some extent, these and other studies also dampened the general appeal of prostate cancer chemoprevention, because validation of effective agents requires extremely large and expensive trials with long follow-up to show potentially modest benefits. Nonetheless, the importance of chemoprevention strategies should not be understated, particularly for advanced disease, because the most efficient way to address metastatic or lethal prostate cancer is to suppress its formation in the first place.

At present, a wide range of strategies are being harnessed to improve prostate cancer treatment. For example, new approaches for targeted therapy are addressing the combination of 
epigenetic inhibitors or radiation therapy with the use of current state of the art anti-androgens. In particular, despite initial lack of successes with immunotherapy, new approaches are being developed to incorporate immunotherapy as part of the treatment repertoire. Finally, molecular advances in patient imaging have greatly enhanced the diagnosis and treatment of prostate cancer and are vital for monitoring clinical trials.

\section{HOW CAN RESEARCH INTO PROSTATE CANCER BECOME MORE EFFECTIVE?}

Experimental analyses of prostate cancer have long been hampered by the relative lack of cell lines that recapitulate the different stages of the disease. Until recently, most studies of prostate cancer have used the same handful of cell lines that have idiosyncratic features that may not be representative for modeling many aspects of prostate cancer. Thus, the advent of sophisticated three-dimensional cell culture approaches to generate organoid models of prostate cancer has provided exciting new approaches for studying prostate cancer in the laboratory (Chua et al. 2014; Karthaus et al. 2014). To date, however, human prostate tumor organoid lines have only been established from metastatic CRPC, and not yet from primary tumors, which may limit the general applicability of this approach (Gao et al. 2014; Puca et al. 2018). In addition, further advances are needed in the development of cell culture models that accurately reflect human prostate cancer, including models with intact immune systems that can be used to study tumor-immune interactions.

Advances in genetically engineered mouse models have led to accurate modeling of multiple facets of prostate tumor initiation and progression. Such studies invariably confront the issue of whether mouse models can accurately reflect human prostate cancer, or at least specific features of human prostate tumors (Ittmann et al. 2013). At the molecular level, it is now evident that genetically engineered mice can indeed model key aspects of regulatory interactions and signaling pathways that are fundamental for human prostate tumorigenesis (Aytes et al. 2014). Thus, numerous studies have exploited cross-species approaches to elucidate central and conserved mechanisms that underlie prostate cancer.

Furthermore, the ability to analyze drug response of genetically engineered mouse models has already led to substantial efforts to create a "mouse hospital" for coclinical analyses of drug response, with initially promising results (Clohessy and Pandolfi 2015). As a complementary approach, the establishment of many novel patient-derived xenograft lines also provides opportunities for studying prostate cancer progression and drug response. However, the limitations of mouse models in terms of potential species-specific differences in physiology and pharmacokinetics, as well as basic anatomical differences between the structure of the rodent and human prostate, remain formidable challenges for the implementation of coclinical studies involving mouse models.

\section{AT THE CROSSROADS-A TIME TO REFLECT}

Despite the wealth of new technologies that have been brought to bear on prostate cancer, many significant challenges remain. Thus, we believe that this is a timely moment to step back and contemplate the progress that the field has made, and what future directions seem most promising to pursue. We hope that the readers of this collection find this survey of the field inspires further efforts and share our appreciation for the outstanding accomplishments made by the dedicated scientists and clinicians who pursue research on prostate cancer.

\section{REFERENCES}

Andriole GL, Crawford ED, Grubb RL III, Buys SS, Chia D, Church TR, Fouad MN, Gelmann EP, Kvale PA, Reding DJ, et al. 2009. Mortality results from a randomized prostate-cancer screening trial. N Engl J Med 360: 1310 1319.

Ang JE, Olmos D, de Bono JS. 2009. CYP17 blockade by abiraterone: Further evidence for frequent continued hormone-dependence in castration-resistant prostate cancer. Br J Cancer 100: 671-675.

Antonarakis ES, Lu C, Wang H, Luber B, Nakazawa M, Roeser JC, Chen Y, Mohammad TA, Chen Y, Fedor HL, 
M.M. Shen and M.A. Rubin

et al. 2014. AR-V7 and resistance to enzalutamide and abiraterone in prostate cancer. N Engl J Med 371: 10281038.

Armenia J, Wankowicz SAM, Liu D, Gao J, Kundra R, Reznik E, Chatila WK, Chakravarty D, Han GC, Coleman I, et al. 2018. The long tail of oncogenic drivers in prostate cancer. Nat Genet 50: 645-651.

Aytes A, Mitrofanova A, Lefebvre C, Alvarez MJ, CastilloMartin M, Zheng T, Eastham JA, Gopalan A, Pienta KJ, Shen MM, et al. 2014. Cross-species regulatory network analysis identifies a synergistic interaction between FOXM1 and CENPF that drives prostate cancer malignancy. Cancer Cell 25: 638-651.

Barbieri CE, Baca SC, Lawrence MS, Demichelis F, Blattner M, Theurillat JP, White TA, Stojanov P, Van Allen E, Stransky N, et al. 2012. Exome sequencing identifies recurrent SPOP, FOXA1 and MED12 mutations in prostate cancer. Nat Genet 44: 685-689.

Beltran H, Rickman DS, Park K, Chae SS, Sboner A, MacDonald TY, Wang Y, Sheikh KL, Terry S, Tagawa ST, et al. 2011. Molecular characterization of neuroendocrine prostate cancer and identification of new drug targets. Cancer Discov 1: 487-495.

Blattner M, Lee DJ, O'Reilly C, Park K, MacDonald TY, Khani F, Turner KR, Chiu YL, Wild PJ, Dolgalev I, et al 2014. SPOP mutations in prostate cancer across demographically diverse patient cohorts. Neoplasia 16: 14-20.

Bray F, Ferlay J, Soerjomataram I, Siegel RL, Torre LA, Jemal A. 2018. Global cancer statistics 2018: GLOBOCAN estimates of incidence and mortality worldwide for $36 \mathrm{can}$ cers in 185 countries. CA Cancer J Clin doi: 10.3322/ caac. 21492 .

Cancer Genome Atlas Research Network. 2015. The molecular taxonomy of primary prostate cancer. Cell 163: 1011-1025.

Chen CD, Welsbie DS, Tran C, Baek SH, Chen R, Vessella R, Rosenfeld MG, Sawyers CL. 2004. Molecular determinants of resistance to antiandrogen therapy. Nat Med 10: 33-39.

Chua CW, Shibata M, Lei M, Toivanen R, Barlow LJ, Bergren SK, Badani KK, McKiernan JM, Benson MC, Hibshoosh $\mathrm{H}$, et al. 2014. Single luminal epithelial progenitors can generate prostate organoids in culture. Nat Cell Biol 16: 951-961.

Clohessy JG, Pandolfi PP. 2015. Mouse hospital and co-clinical trial project-from bench to bedside. Nat Rev Clin Oncol 12: 491-498.

Cunha GR, Donjacour AA, Cooke PS, Mee S, Bigsby RM, Higgins SJ, Sugimura Y. 1987. The endocrinology and developmental biology of the prostate. Endocr Rev 8: 338-362.

Gao D, Vela I, Sboner A, Iaquinta PJ, Karthaus WR, Gopalan A, Dowling C, Wanjala JN, Undvall EA, Arora VK, et al 2014. Organoid cultures derived from patients with advanced prostate cancer. Cell 159: 176-187.

Hieronymus H, Murali R, Tin A, Yadav K, Abida W, Moller H, Berney D, Scher H, Carver B, Scardino P, et al. 2018. Tumor copy number alteration burden is a pan-cancer prognostic factor associated with recurrence and death. eLife 7: e37294.

Hu JC, Nguyen P, Mao J, Halpern J, Shoag J, Wright JD, Sedrakyan A. 2017. Increase in prostate cancer distant metastases at diagnosis in the United States. JAMA Oncol 3: 705-707.

Huang FW, Mosquera JM, Garofalo A, Oh C, Baco M, Amin-Mansour A, Rabasha B, Bahl S, Mullane SA, Robinson $\mathrm{BD}$, et al. 2017. Exome sequencing of AfricanAmerican prostate cancer reveals loss-of-function ERF mutations. Cancer Discov 7: 973-983.

Ittmann M, Huang J, Radaelli E, Martin P, Signoretti S, Sullivan R, Simons BW, Ward JM, Robinson BD, Chu GC, et al. 2013. Animal models of human prostate cancer: The consensus report of the New York meeting of the Mouse Models of Human Cancers Consortium Prostate Pathology Committee. Cancer Res 73: 2718-2736.

Karthaus WR, Iaquinta PJ, Drost J, Gracanin A, van Boxtel R, Wongvipat J, Dowling CM, Gao D, Begthel H, Sachs N, et al. 2014. Identification of multipotent luminal progenitor cells in human prostate organoid cultures. Cell 159: 163-175.

Ku SY, Rosario S, Wang Y, Mu P, Seshadri M, Goodrich ZW, Goodrich MM, Labbe DP, Gomez EC, Wang J, et al. 2017. $R b 1$ and $\operatorname{Tr} p 53$ cooperate to suppress prostate cancer lineage plasticity, metastasis, and antiandrogen resistance. Science 355: 78-83.

Kwon OJ, Zhang L, Ittmann MM, Xin L. 2014. Prostatic inflammation enhances basal-to-luminal differentiation and accelerates initiation of prostate cancer with a basal cell origin. Proc Natl Acad Sci 111: E592-E600.

Locke JA, Guns ES, Lubik AA, Adomat HH, Hendy SC, Wood CA, Ettinger SL, Gleave ME, Nelson CC. 2008. Androgen levels increase by intratumoral de novo steroidogenesis during progression of castration-resistant prostate cancer. Cancer Res 68: 6407-6415.

Miyamoto DT, Zheng Y, Wittner BS, Lee RJ, Zhu H, Broderick KT, Desai R, Fox DB, Brannigan BW, Trautwein J, et al. 2015. RNA-Seq of single prostate CTCs implicates noncanonical Wnt signaling in antiandrogen resistance. Science 349: 1351-1356.

Montgomery RB, Mostaghel EA, Vessella R, Hess DL, Kalhorn TF, Higano CS, True LD, Nelson PS. 2008. Maintenance of intratumoral androgens in metastatic prostate cancer: A mechanism for castration-resistant tumor growth. Cancer Res 68: 4447-4454.

Mostaghel EA, Page ST, Lin DW, Fazli L, Coleman IM, True LD, Knudsen B, Hess DL, Nelson CC, Matsumoto AM, et al. 2007. Intraprostatic androgens and androgen-regulated gene expression persist after testosterone suppression: Therapeutic implications for castration-resistant prostate cancer. Cancer Res 67: 5033-5041.

Mu P, Zhang Z, Benelli M, Karthaus WR, Hoover E, Chen CC, Wongvipat J, Ku SY, Gao D, Cao Z, et al. 2017. SOX2 promotes lineage plasticity and antiandrogen resistance in TP53- and RB1-deficient prostate cancer. Science 355: 84-88.

Puca L, Bareja R, Prandi D, Shaw R, Benelli M, Karthaus WR, Hess J, Sigouros M, Donoghue A, Kossai M, et al. 2018. Patient derived organoids to model rare prostate cancer phenotypes. Nat Commun 9: 2404.

Robinson D, Van Allen EM, Wu YM, Schultz N, Lonigro RJ, Mosquera JM, Montgomery B, Taplin ME, Pritchard CC, Attard G, et al. 2015. Integrative clinical genomics of advanced prostate cancer. Cell 161: 1215-1228. 
Schroder FH, Hugosson J, Roobol MJ, Tammela TL, Ciatto S, Nelen V, Kwiatkowski M, Lujan M, Lilja H, Zappa M, et al. 2009. Screening and prostate-cancer mortality in a randomized European study. N Engl J Med 360: 1320-1328.

Shoag JE, Mittal S, Hu JC. 2016. Reevaluating PSA testing rates in the PLCO Trial. N Engl J Med 374: 1795-1796.

Siegel RL, Miller KD, Jemal A. 2018. Cancer statistics, 2018. CA Cancer J Clin 68: 7-30.

Thompson IM, Goodman PJ, Tangen CM, Lucia MS, Miller GJ, Ford LG, Lieber MM, Cespedes RD, Atkins JN, Lippman SM, et al. 2003. The influence of finasteride on the development of prostate cancer. N Engl J Med 349: 215-224.

Toivanen R, Mohan A, Shen MM. 2016. Basal progenitors contribute to repair of the prostate epithelium following induced luminal anoikis. Stem Cell Rep 6: 660-667.

Tomlins SA, Rhodes DR, Perner S, Dhanasekaran SM, Mehra R, Sun XW, Varambally S, Cao X, Tchinda J, Kuefer R, et al. 2005. Recurrent fusion of TMPRSS2 and ETS transcription factor genes in prostate cancer. Science 310: 644-648.

Tran C, Ouk S, Clegg NJ, Chen Y, Watson PA, Arora V, Wongvipat J, Smith-Jones PM, Yoo D, Kwon A, et al. 2009. Development of a second-generation antiandrogen for treatment of advanced prostate cancer. Science 324: $787-790$

US Preventive Services Task Force, Grossman DC, Curry SJ, Owens DK, Bibbins-Domingo K, Caughey AB, Davidson KW, Doubeni CA, Ebell M, Epling JW Jr, et al. 2018. Screening for prostate cancer: US Preventive Services Task Force Recommendation Statement. JAMA 319: 1901-1913.

Zou M, Toivanen R, Mitrofanova A, Floch N, Hayati S, Sun Y, Le Magnen C, Chester D, Mostaghel EA, Califano A, et al. 2017. Transdifferentiation as a mechanism of treatment resistance in a mouse model of castration-resistant prostate cancer. Cancer Discov 7: 736-749. 


\section{$\&_{\mathrm{CSH}}^{\infty} \&$ Cold Spring Harbor

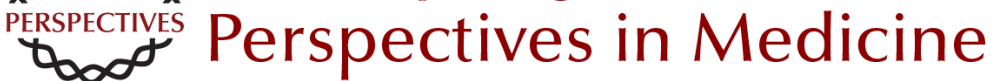

\section{Prostate Cancer Research at the Crossroads}

Michael M. Shen and Mark A. Rubin

Cold Spring Harb Perspect Med 2019; doi: 10.1101/cshperspect.a036277 originally published online October 22, 2018

\section{Subject Collection Prostate Cancer}

Anatomic and Molecular Imaging in Prostate Cancer

Eric T. Miller, Amirali Salmasi and Robert E. Reiter

The Epidemiology of Prostate Cancer

Claire H. Pernar, Ericka M. Ebot, Kathryn M. Wilson, et al.

Prostate Stem Cells and Cancer Stem Cells Jia J. Li and Michael M. Shen

Prostate Cancer Epigenetics: From Basic Mechanisms to Clinical Implications Srinivasan Yegnasubramanian, Angelo M. De Marzo and William G. Nelson

\section{The Genomics of Prostate Cancer: A Historic} Perspective Mark A. Rubin and Francesca Demichelis

Neuroendocrine Differentiation in Prostate

Cancer: Emerging Biology, Models, and Therapies Loredana Puca, Panagiotis J. Vlachostergios and Himisha Beltran

DNA Damage Response in Prostate Cancer Matthew J. Schiewer and Karen E. Knudsen

Transcriptional Regulation in Prostate Cancer David P. Labbé and Myles Brown
New Opportunities for Targeting the Androgen Receptor in Prostate Cancer Margaret M. Centenera, Luke A. Selth, Esmaeil Ebrahimie, et al.

Prostate Cancer Research at the Crossroads Michael M. Shen and Mark A. Rubin

Immunotherapy for Prostate Cancer Nicholas J. Venturini and Charles G. Drake

Molecular Pathology of High-Grade Prostatic Intraepithelial Neoplasia: Challenges and Opportunities Levent Trabzonlu, Ibrahim Kulac, Qizhi Zheng, et al.

Metastases in Prostate Cancer Federico La Manna, Sofia Karkampouna, Eugenio Zoni, et al.

Genetically Engineered Mouse Models of Prostate Cancer in the Postgenomic Era Juan M. Arriaga and Cory Abate-Shen

Molecular Biomarkers in the Clinical Management of Prostate Cancer Aaron M. Udager and Scott A. Tomlins

Metabolic Vulnerabilities of Prostate Cancer: Diagnostic and Therapeutic Opportunities Giorgia Zadra and Massimo Loda

For additional articles in this collection, see http://perspectivesinmedicine.cshlp.org/cgi/collection/ 